"Molecular Physics and Sound," and "The First Book of Knowledge."

He was elected a Fellow of the Royal Society of Edinburgh in 1859 , and a Fellow of the Royal Society of London in 1873 .

G. C. F.

\section{THE LONGEVITY OF GREAT MEN}

$\mathrm{THE}$ conclusion that the intellectual giants of the race are favoured by an abundance of years on the scene of their heroic activity, and are thus further differentiated from their more common fellow-men, seems natural, and has been accepted upon evidence which, in a less pleasing conclusion, would be considered ridiculously insufficient, and even false. The usual method of attempting to answer the question whether great men are longer-lived than others, is to prepare a list of the ages, at death, of a number of eminent men, take the average age, and compare it with a similar average of a number of ordinary men, or even with the average lifetime of the race, and in this way to make the results speak decidedly in favour of the superior longevity of great men. All that such a method can prove (and this it does prove) is that it takes long to become great. It neglects to consider that a select class of men is dealt with, and that, to be even potentially included in this class, one must have lived a certain number of years.

For example: in an article translated in the Popular Science Monthly for May 1884 , it is argued that astronomers are a long-lived race because the average lifeperiod of $174 \mathrm{I}$ astronomers is 64 years and 3 months. An average human life is only 33 years; but as one cannot be an astronomer before adult life, the author takes the expectation of life at 18 years, which is 6 I years, and thus makes an excess of over 3 years in favour of astronomers. $\mathrm{He}$ also divides his astronomers into four degrees of eminence, and finds that those of the first rank live longer than those of the second, and they in turn longer than those of the third, and so on, thus implying that the best astronomers are most favoured with years. The true conclusion is, that it takes longer to become a firstrank astronomer than it does to become a less eminent one. $^{2}$

If great men were great from their infancy, and we had the means of ascertaining this fact, the method would be correct. But, as it is, we must define in some way or other what we mean by greatness, and then fix the average age at which it becomes possible to distinguish an amount of talent sufficient to enable its possessor to be enrolled in the ranks of the great as already defined. What is known as the "expectation of life" at any number of years tells the most probable age at death of one who has attained the years under consideration : a comparison of this age with the age at death of great men will decide whether they are longer-lived or not.

The attempt was made to select about 280 to 300 of the greatest men that ever lived. ${ }^{3}$ Throwing out about 30 of the doubtful names, there remain 250 men, about whom the statement is hazarded that a list of the 250 greatest men, prepared by another set of persons, will not mate-

From Science.

"Mr. Galt $\supset$ ( "Hereditary Genius," p. 34) has allowed himself to neglect a similar cons.deration. In giving the number of men in each class that the population of the Un.ted Kingdom wc uld have between certain ages, he gives 35 as the number of men of class $G$ (a very high degree of eminence) between the ages 20 and 30 , and only 21 such men between 40 and 50 years. But this cannot be true, because only a very sma'l proportion of men could possibly attain the eminence requisite to be classed among the $G^{\prime} \mathrm{s}$ in 20 to 3 o years, while almost all (of those who will attain it at all) will have attained it before the end of their fiftieth year. And this consideration far outbalances the excess in absolute number of men between the former ages over those between the latter. Similarly the falling-off in the number of men of class $g$, i.e. idiots, from decade to decade, would be more rapid than in ordinary men, - a fact which the tables fail to show.

3 'The names were selected by three others and myself, while engaged in a study of what might be called the natural history of great men. 'I'he pr cess of selection was most rigid and careful, by a system which it would take too long to describe. rially differ from our list, as far as all the purposes for which it is to be used are concerned. From this list I have selected at random a set of men of whom it was probably easy to fix the age at which they had done work which would entitle them to a place on this list, or work which almost inevitably led to such distinction: it is a date about midway between the first important work and the greatest work. The average of over 60 such ages is 37 years; which means, that, on the average, a man must be 37 years old in order to be a candidate for a place on this list. The real question, then, is, How does the longevity of this select class of 37 -year-old men compare with that of more ordinary individuals? The answer is given by the expectation of life at 37 years, which is 29 years, making the average age at death 66 years. And this is precisely the age at death of the 3 e 60 great men ; showing, that, as a class (for these 60 may be considered a fair sample), great men are not distinguished by their longevity from other men.

Further interesting conclusions can be drawn if we divide the men into classes, according to real psychological and physiological differences in the ways of manifestation of the several kinds of genius. It is almost surprising how well the ordinary trinity of facultiesintellect, emotions, and will-accomplishes this purpose. Greatness seems to appear either in a brilliant thought, a deep feeling, or a powerful will. Under men of thought would be included philosophers, scientists, historians, \&c.; under men of feeling, poets, musicians, religionists, \&c.; under men of action, rulers, commanders, statesmen, \&c. Before comparing the relative longevity of these three classes of men, I assure myself that the period at which greatness begins to be possible does not materially differ ${ }^{1}$ in the three classes, and, as was done in the former case, I exclude all cases of unnatural death. I find that men of thought live $69^{\circ} 5$ years, or $3^{\circ} 5$ years longer than ordinary men; while the lives of men of feeling are 3 years, those of men of action 5 years, shorter than those of average men,- a conclusion that agrees with the commonly accepted view on the subject. If we subdivide these three classes, we find, that, while all classes of men of thought live longer than ordinary men, the moralists live longest, scientists coming next; that among the men of feeling the religionists alone live the full period of life, while poets' lives are 5 years, and musicians' lives 8 years, too short ; that, of men of action, rulers and commanders both fail to complete the full term of life by 4 years. One sees from these statements (which, however, in their detail at least, must be accepted with hesitation, owing to the fewness of examples) that the kind of psychical and physical activity pursued influences the life-period; that certain types of genius are apt to die young, while others are particularly favoured with a full allowance of years.

The question of longevity becomes important when we consider that through it the leaders of civilisation are allowed to exercise their important function a few years longer, thus enabling more great men to be alive at the same time; and that, by its tendency to be inherited by the offspring, the children of great men will begin life with a better chance of reaching maturity, and, in turn, of becoming important to the world, if, as we have reason to believe it would, the genius of their ancestors has left its traces in them.

JOSEPH JASTROW

\section{THE GEOLOGY OF THE LEBANON}

WE are indebted to Dr. Carl Diener, of the University of Vienna, for an able monograph on the geological and physical formation of the Lebanon and surrounding districts, accompanied by maps, sections, and

${ }^{I}$ Mr. Sully (Nineteenth Century, June 1886) has shown that men of feeling are more precocious than men of thought; but the difference in the age at which their first great work is done, though,in favour of men of feeling, is very slight indeed. 